\title{
Aplikasi Computer-Based Test Ujian pada SMP Negeri 6 Cimahi
}

\author{
Rizqy Dyah Utami \\ Program Studi Sistem Informasi, Universitas Komputer Indonesia \\ Jl. Dipatiukur No. 112-116, Bandung, 40132, Indonesia \\ rdyahutm@gmail.com \\ diterima: 12 Agustus 2019 \\ direvisi: 28 September 2019 \\ dipublikasi: 30 September 2019
}

\begin{abstract}
Abstrak
Aplikasi Computer-Based Test (CBT) merupakan salah satu bagian e-learning yang dikembangkan dalam pemanfaatan teknologi dan komunikasi di bidang pendidikan. Seluruh siswa di Indonesia harus terbiasa dengan adanya sistem Computer-Based Test (CBT), akan tetapi dalam praktiknya belum banyak sekolah yang memiliki sistem CBT. Dengan adanya sistem CBT, mempermudah guru dan siswa dalam melakukan kegiatan ujian, meminimalisir kesalahan koreksi, dan mengurangi kecurangan ujian yang dilakukan siswa. Oleh karena itu, SMP Negeri 6 Cimahi membutuhkan sistem CBT untuk mengurangi permasalahan tersebut. Metode pengembangan yang akan digunakan adalah prototype, penulis melakukan observasi dan wawancara dalam pengumpulan data. Sedangkan, untuk metode pendekatan sistem menggunakan OOP (Object Oriented Programming) dengan pemodelan UML (Unified Modeling Language). Implementasi dari aplikasi Computer-Based Test (CBT) ujian, dibuat dalam modul pembuatan soal dan jawaban, pengerjaan ujian, penilaian, dan pembahasan soal.
\end{abstract}

Kata kunci: Aplikasi; CBT; Ujian; SMP Negeri 6 Cimahi

\begin{abstract}
Computer-Based Test (CBT) application is part of e-learning developed use technology and communication in the education. All students in Indonesia must be familiar with the existence of a Computer-Based Test (CBT) system, but in practice not many schools have a $C B T$ system. With the CBT system, it makes it easier for teachers and students to carry out exam activities, minimize correction errors, and reduce exam fraud by students. Therefore, SMP Negeri 6 Cimahi needs a CBT system to reduce these problems. The development method use prototype, the author makes observations and interviews in data collection. Whereas, for the system approach method uses OOP (Object Oriented Programming) with UML (Unified Modeling Language) modeling. The implementation of Computer-Based Test (CBT) exam application, made in the module making questions and answers, working on examinations, assessments, and discussion questions.
\end{abstract}

Keywords: Application; CBT; Exam; SMP Negeri 6 Cimahi 


\section{Pendahuluan}

Perkembangan Information and Communication Technologies (ICT) sesuai dengan kebutuhan penggunanya dan bertujuan untuk memudahkan setiap aktifitas. Sehingga, teknologi informasi dan komunikasi sangat dibutuhkan dalam berbagai bidang. Pengaruh teknologi informasi dan komunikasi juga berdampak pada kemajuan teknologi di bidang pendidikan yang pada saat ini mengalami peningkatan dalam hal kemudahan dan kecepatan. Teknologi juga menjadi salah satu langkah strategis dalam mewujudkan pencapaian akan masa depan sesuai dengan visi misi. Termasuk didalamnya pada bidang Pendidikan, yakni guna menciptakan ruang belajar digital yang ideal. [1][2]

Salah satu pemanfaatan teknologi informasi dan komunikasi dalam bidang pendidikan antara lain dengan membangun aplikasi Computer-Based Test (CBT). Menurut AJ Romiszowski, Computer-Based Test (CBT) adalah sistem yang menyerupai Computer Managed Instruction (CMI). CMI adalah strategi pembelajaran yang menggunakan komputer sebagai tujuan dan sumber pembelajaran serta penilaian terhadap siswa. CBT dapat digunakan untuk membuat pengujian berdasarkan tingkat kesulitan yang tidak dapat digunakan pada pembelajaran konvensional di dalam kelas. [3]

Pada penelitian yang dilakukan di SMP Negeri 6 Cimahi, ujian yang dilakukan masih menggunakan metode konvensional yang menyebabkan hilangnya lembar jawaban ujian siswa pada saat proses pengumpulan kepada guru. Sebelum pelaksanaan ujian, guru harus membuat soal ujian harian, UTS, maupun UAS. Lembar soal tersebut harus diperbanyak lagi oleh bagian tata usaha sehingga sekolah harus menanggung beban biaya percetakan soal. Soal yang dibuat oleh guru cenderung sama untuk setiap siswa dan menimbulkan kecurangan karena adanya kesempatan untuk mencontek. Setelah proses ujian, guru harus melakukan koreksi hasil ujian yang membutuhkan waktu yang relatif lama dan berpotensi mengalami kesalahan dalam penilaian.

Dengan memanfaatkan aplikasi CBT ujian berbasis web, diharapkan dapat meminimalisir hilangnya lembar jawaban siswa. Diharapkan juga dapat menjadi aplikasi yang efisien untuk pembuatan soal karena soal dibuat oleh guru atau admin tanpa harus melalui perantara. Dan dengan adanya fitur acak soal mengurangi kecurangan siswa yang mencontek saat ujian. Fitur nilai yang dapat mengkoreksi jawaban ujian dengan cepat dan meminimalisir kesalahan penilaian. Maka penulis menilai perlu dibuatnya suatu aplikasi CBT ujian berbasis web yang dapat diakses oleh admin, guru, maupun siswa sehingga mendukung proses ujian dengan menggunakan komputer dan internet. Selain itu, aplikasi CBT juga diharapkan dapat dilakukan sebagai pembiasaan siswa terhadap sistem ujian online yang digunakan pada saat ujian nasional di tingkat IX. Berdasarkan uraian permasalahan tersebut, penulis tertarik untuk mengambil judul penelitian, "APLIKASI COMPUTER-BASED TEST (CBT) UJIAN PADA SMP NEGERI 6 CIMAHI”.

\section{Kajian Pustaka}

Aplikasi computer-based test (CBT) ujian adalah sistem pelaksanaan tes atau ujian yang menggunakan media komputer dan internet dalam hal penyampaian soal dan pengerjaan soal. Aplikasi ini diharapkan bisa meminimalisir kecurangan dan kebocoran soal yang kerap terjadi karena ujian dengan metode paper-based test (PBT). Berikut ini teori yang melatarbelakangi adanya aplikasi computer-based test (CBT) ujian :

Menurut O'Brien, sistem informasi adalah gabungan atau kombinasi yang teratur dari beberapa aspek pendukung sistem infomasi yaitu people, hardware, software, computer networks, data communications dan database yang mampu mengumpulkan, mengubah dan menyebarkan informasi di dalam organisasi [4]. Selanjutnya, Robert A. Leitch dan K. Roscoe Davis berpendapat dalam buku Jogiyanto bahwa sistem informasi adalah suatu 
sistem yang berada di dalam organisasi yang menghubungkan berbagai kegiatan seperti pengolahan data transaksi harian, mendukung kegiatan operasi, sifatnya manajerial dan kegiatan strategi organisasi yang dapat terhubung juga dengan pihak eksternal organisasi terkait laporan yang diperlukan [5]. Berdasarkan pendapat ahli diatas, penulis menyimpulkan bahwa sistem informasi adalah kumpulan berbagai komponen yang terdiri dari hardware, software, database, jaringan komputer, komunikasi data, dan orang yang terlibat dalam suatu sistem dan berkolaborasi untuk menghasilkan informasi yang dapat digunakan oleh pengguna.

Computer-Based Test (CBT) merupakan perkembangan dari sistem informasi elearning. E-learning merupakan sistem pembelajaran dengan memanfaatkan media elektronik (LAN, WAN, dan internet) baik secara formal maupun informal untuk menyampaikan materi pembelajaran dan interaksi antara guru dan siswa [6][7]. Maka, dapat disimpulkan bahwa Computer-Based Test (CBT) merupakan bagian dari sistem elearning. Menurut Azhar Arsyad, CBT adalah pemanfaatan komputer sebagai media yang digunakan dalam pembelajaran secara general yang dibuat mengikuti proses instruksional seperti mengorganisasikan dan menjadwalkan pengajaran, penilaian tes pada siswa, kumpulan data siswa, analisis data pembelajaran, catatan perkembangan pembelajaran, dan ujian dengan permutasi soal yang acak [8][9]. Dari definisi ahli diatas, penulis menyimpulkan bahwa computer-based test (CBT) adalah pemanfaatan teknologi komputer dan internet yang digunakan sebagai media pelaksanaan ujian atau test yang mengubah cara ujian konvensional menjadi ujian berbasis komputer.

\section{Metode Penelitian}

Pada penelitian ini, penulis menggunakan pendekatan sistem berorientasi objek atau OOP (Object Oriented Programming), serta digunakannya diagram-diagram UML (Unifield Modelling Language) sebagai alat bantu analisis dan perancangan sistem.

\subsection{Metode Pengembangan Sistem}

Pada penelitian ini, penulis menggunakan metode pengembangan sistem metode prototyping. Pada metode prototyping, pengembang sistem informasi mengembangkan suatu sistem yang sesuai dengan kebutuhan pelanggannya. Roger. S. Pressman menguraikan tiga tahapan pengembangan sistem dengan metode prototyping. Tahap pertama adalah mendengarkan pelanggan, seorang pengembang sistem informasi harus dapat memahami kebutuhan pelanggannya. Jadi, mendengarkan pelanggan merupakan tahap yang penting sebelum pengembang sistem informasi melakukan tahapan selanjutnya dalam mengembangkan sistem. Tahap kedua, membangun prototype sistem berdasarkan kebutuhan pelanggan yang sudah diuraikan pada tahap pertama. Setelah membangun prototype selesai, pelanggan akan melakukan pengujian dan evaluasi terhadap prototype yang dibuat pengembang sistem. Pengujian pelanggan merupakan tahap akhir dari metode pengembangan protoyping[10].

\subsection{Analisis Sistem yang Berjalan}

Analisis sistem yang berjalan menjelaskan bagaimana aktifitas pada sistem yang sedang berlangsung di sekolah tersebut yang berkaitan dengan pembangunan aplikasi CBT ujian, kemudian diklasifikasikan juga aktor yang terlibat dalam sistem dan alur aktifitas pada sistem yang berjalan. 


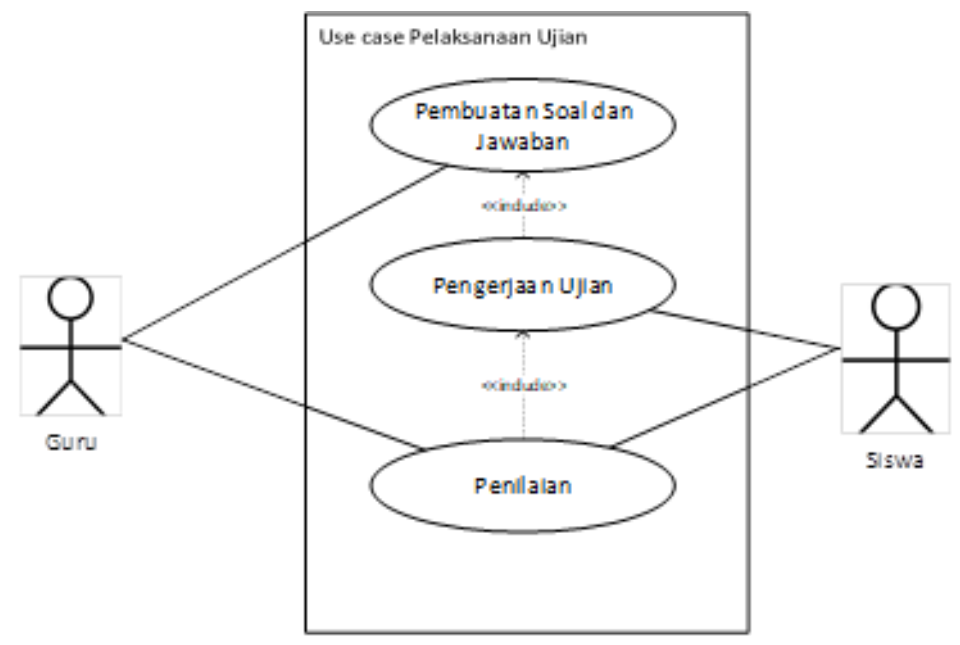

Gambar 1. Use case yang sedang berjalan

\subsection{Evaluasi Sistem yang Berjalan}

Dari analisis yang telah dilakukan pada sistem ujian harian, UTS, dan UAS di SMP Negeri 6 Cimahi, maka perancangan sistem dengan memanfaatkan teknologi yang terus menerus berkembang perlu dilakukan untuk dapat mengatasi masalah yang ada pada sistem yang sedang berjalan. Berikut ini uraian evaluasi terhadap sistem ujian harian, UTS, dan UAS yang sedang berjalan.

Tabel 1. Evaluasi sistem yang sedang berjalan

\begin{tabular}{|c|l|l|}
\hline No & \multicolumn{1}{|c|}{ Permasalahan } & \multicolumn{1}{|c|}{ Penyelesaian } \\
\hline 1. & $\begin{array}{l}\text { Guru membuat soal dan jawaban } \\
\text { yang harus diperbanyak lagi oleh } \\
\text { bagian Tata Usaha. }\end{array}$ & $\begin{array}{l}\text { Membuat sistem informasi yang } \\
\text { memfasilitasi guru untuk membuat soal } \\
\text { dan jawaban secara langsung tanpa melalui } \\
\text { perantara. }\end{array}$ \\
\hline 2. & $\begin{array}{l}\text { Guru melakukan penilaian terhadap } \\
\text { hasil ujian siswa pada ujian mata } \\
\text { pelajaran tertentu. }\end{array}$ & $\begin{array}{l}\text { Membuat sistem informasi yang dapat } \\
\text { melakukan penilaian otomatis terhadap } \\
\text { ujian yang dikerjakan siswa. }\end{array}$ \\
\hline 3. & $\begin{array}{l}\text { Guru mencatat nilai hasil ujian siswa } \\
\text { yang kemudian membuat } \\
\text { pengumuman nilai kepada siswa. }\end{array}$ & $\begin{array}{l}\text { Membuat sistem informasi yang memiliki } \\
\text { fitur rekap nilai untuk guru. }\end{array}$ \\
\hline 4. & $\begin{array}{l}\text { Siswa menerima pengumuman nilai } \\
\text { hasil ujian dari guru setelah guru } \\
\text { melakukan penilaian dan pencatatan } \\
\text { nilai. }\end{array}$ & $\begin{array}{l}\text { Membuat sistem informasi yang dapat } \\
\text { menampilkan nilai secara langsung pada } \\
\text { siswa saat ujian selesai. }\end{array}$ \\
\hline
\end{tabular}

\section{Hasil dan Pembahasan}

\subsection{Perancangan Sistem}

Sistem yang diusulkan akan memiliki tiga jenis pengguna atau user yaitu admin, guru dan siswa. Admin sebagai pengelola data pada sistem dan guru serta siswa sebagai pengguna sistem. Setiap pengguna atau user memiliki hak akses berbeda, maka dari itu dibutuhkannya fitur login sebagai keamanan sistem karena dapat memverifikasi user yang akan melakukan login ke sistem. Sistem akan meminta kode user berupa username dan password untuk guru dan NIS (Nomor Induk Siswa) dan password untuk siswa dimana 
kode user tersebut merupakan guru atau siswa yang aktif di lingkungan SMP Negeri 6 Cimahi dan password yang telah dibuat. Kemudian, untuk admin username ataupun password sudah ditentukan.

Aplikasi CBT Ujian yang akan dibuat secara umum adalah menjadikan proses-proses belajar mengajar yang masih manual menjadi terkomputerisasi dan dibagi ke dalam beberapa fitur yang akan diimplementasikan ke sistem. Proses-proses tersebut terdiri dari proses pembuatan soal dan jawaban oleh guru, proses menjawab soal oleh siswa, proses penilaian yang diberikan guru kepada siswa, dan proses pembahasan soal. Dan kemudian proses-proses tersebut dikelola oleh admin dan guru dengan adanya interaksi antara guru, siswa dan sistem.

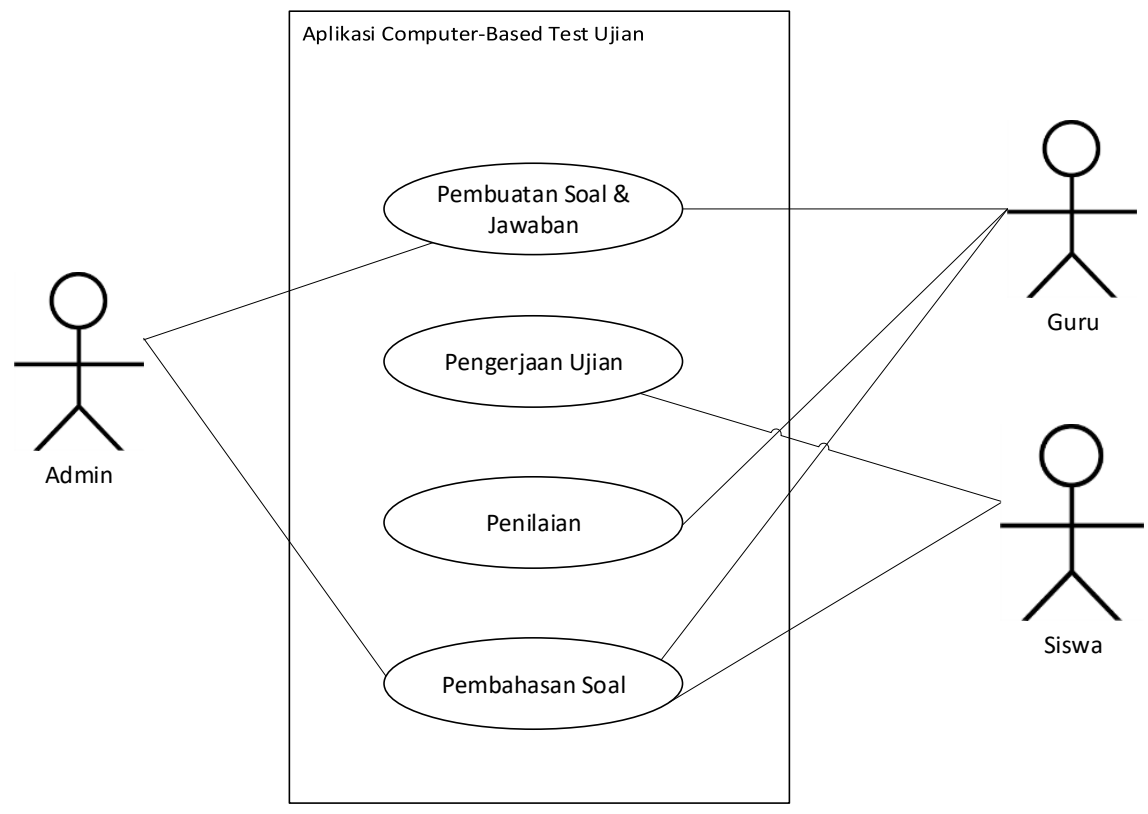

Gambar 2. Usecase yang diusulkan

\section{1) Definisi Aktor dan Deskripsinya}

Aktor adalah orang atau pengguna yang berhubungan dengan sistem. Aktor yang terlibat dalam aplikasi CBT ujian pada SMP Negeri 6 Cimahi adalah:

\begin{tabular}{|c|c|l|}
\hline No & Aktor & \multicolumn{1}{c|}{ Deskripsi } \\
\hline 1 & Admin & $\begin{array}{l}\text { Merupakan aktor yang terlibat dalam proses pengolahan data user } \\
\text { (guru dan siswa) seperti input, edit, dan hapus data user. }\end{array}$ \\
\hline 2 & Guru & $\begin{array}{l}\text { Merupakan aktor yang terlibat dalam proses pembuatan soal dan } \\
\text { jawaban, penilaian, dan pembahasan soal. Aktor guru merupakan } \\
\text { guru mata pelajaran yang bersangkutan. }\end{array}$ \\
\hline 3 & Siswa & $\begin{array}{l}\text { Merupakan aktor yang terlibat dalam proses pengerjaan ujian, } \\
\text { penilaian, dan pembahasan soal. Aktor siswa merupakan siswa yang } \\
\text { mengikuti ujian mata pelajaran yang dibuat oleh guru. }\end{array}$ \\
\hline
\end{tabular}

\section{2) Definisi Use Case dan Deskripsinya}

Berikut ini adalah penjelasan dari usecase dalam aplikasi CBT ujian pada SMP Negeri 6 Cimahi. 
Tabel 3. Definisi Use Case

\begin{tabular}{|c|c|c|}
\hline No & Use Case & Deskripsi \\
\hline 1 & $\begin{array}{l}\text { Pembuatan Soal dan } \\
\text { Jawaban }\end{array}$ & $\begin{array}{l}\text { Merupakan proses yang melibatkan guru dan admin } \\
\text { dalam membuat soal dan jawaban ujian untuk siswa. }\end{array}$ \\
\hline 2 & Pengerjaan Ujian & $\begin{array}{l}\text { Merupakan proses pengerjaan soal ujian yang dibuat oleh } \\
\text { guru dan admin yang kemudian dikerjakan oleh siswa. }\end{array}$ \\
\hline 3 & Penilaian & Merupakan proses penilaian hasil ujian siswa oleh guru. \\
\hline 4 & Pembahasan Soal & $\begin{array}{l}\text { Merupakan proses pembahasan soal dalam bentuk file } \\
\text {.pdf yang dibuat oleh guru dan dapat didownload oleh } \\
\text { siswa. }\end{array}$ \\
\hline
\end{tabular}

\section{3) Implementasi Antarmuka}

Tahap selanjutnya setelah proses perancangan adalah proses implementasi aplikasi yang bertujuan agar dapat digunakan oleh user terkait.

a. Halaman Login Admin dan Guru

Pada tampilan halaman login untuk admin dan guru, terdapat dua textfield yang digunakan untuk mengisi username dan password agar user dapat masuk ke tampilan dashboard untuk admin dan guru.

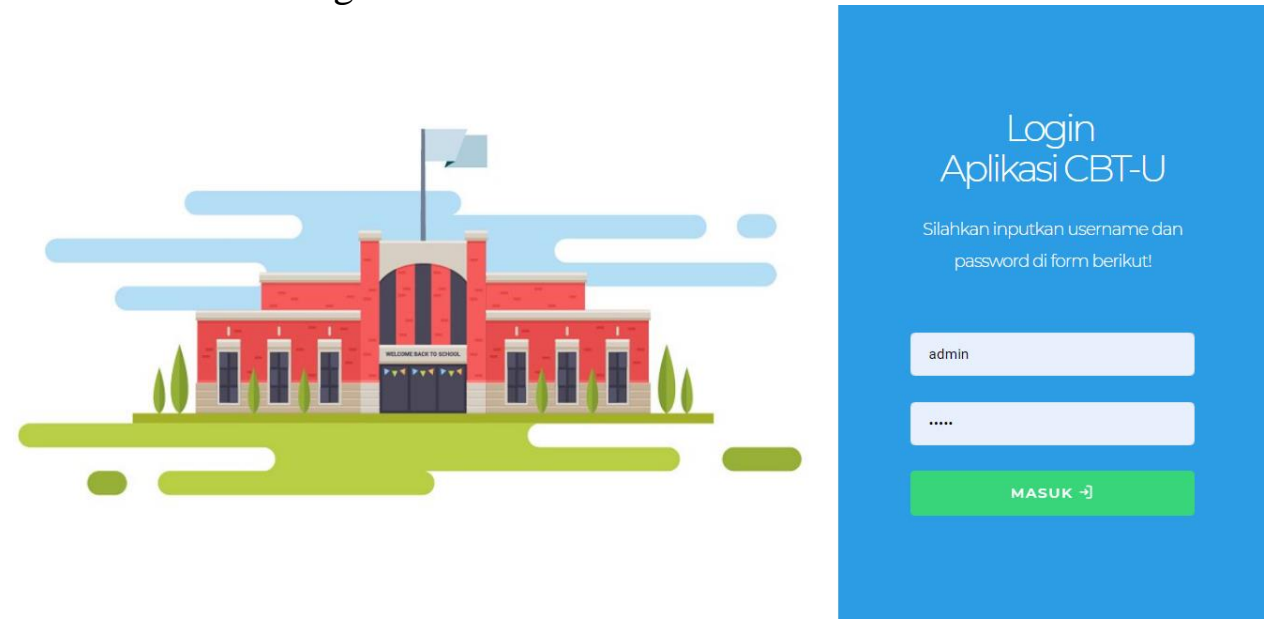

Gambar 1. Halaman Login Admin dan Guru

b. Halaman Login Siswa

Pada tampilan halaman login untuk siswa, terdapat dua textfield yang digunakan untuk mengisi NIS (Nomor Induk Siswa) dan password agar user dapat masuk ke tampilan dashboard untuk siswa. 


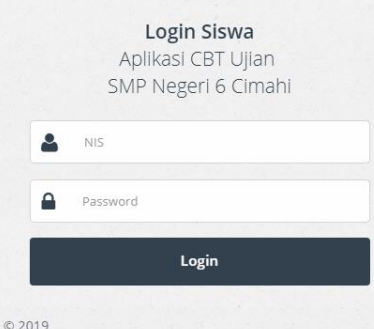

Gambar 2. Halaman Login Siswa

c. Halaman List Ujian (Admin dan Guru)

Halaman list ujian adalah fitur yang digunakan untuk membuat data ujian dan juga mengaktifkan dan menonaktifkan ujian yang telah dibuat sebelumnya.

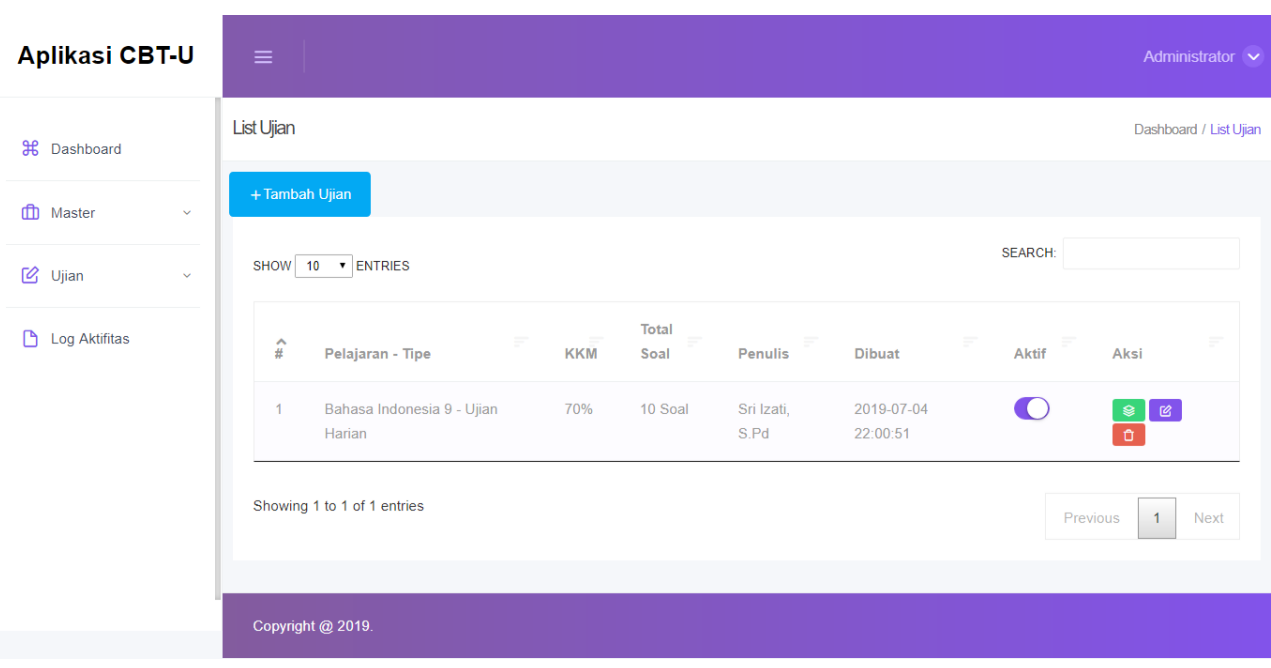

Gambar 3. Halaman List Ujian

d. Halaman Input Data Ujian (Admin dan Guru)

Pada halaman input data ujian, admin dan guru harus mengisi beberapa field yang berhubungan dengan data ujian seperti mata pelajaran, tipe ujian, urutkan soal, nilai kkm, durasi, dan penulis ujian. 


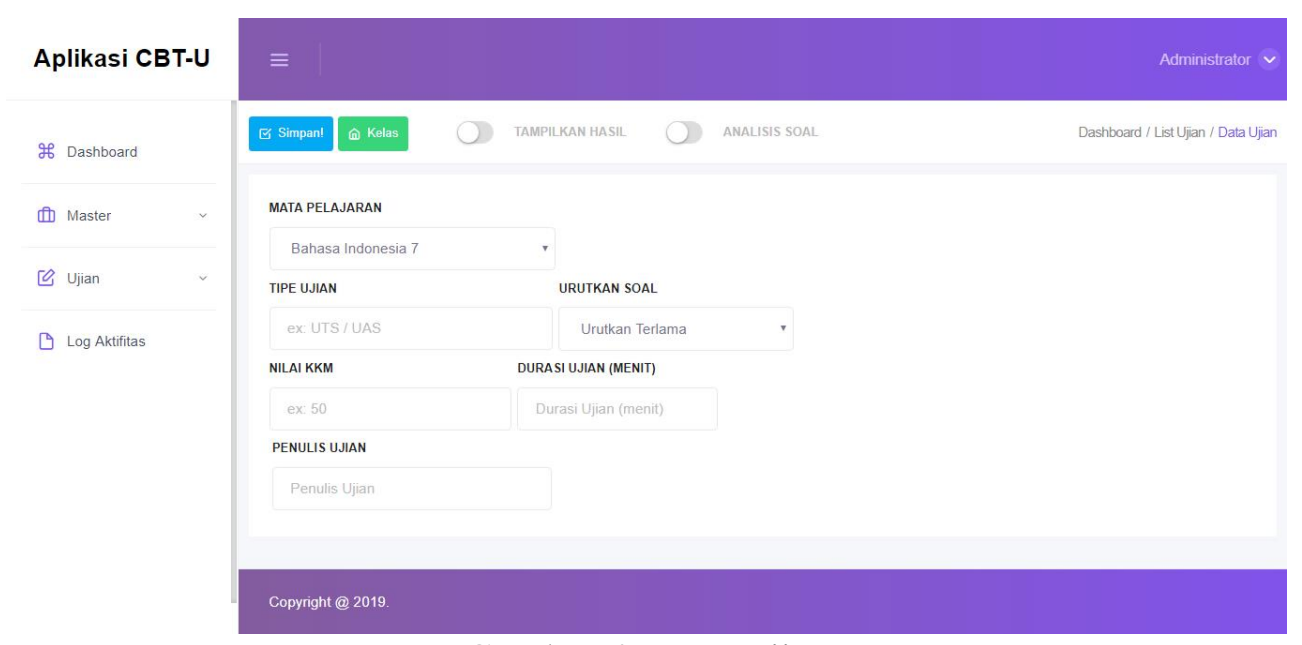

Gambar 4. Data Ujian

\section{e. Halaman Soal (Siswa)}

Halaman soal ditujukan untuk siswa yang sedang mengerjakan ujian, siswa harus mengisi soal yang ada pada halaman aplikasi hingga selesai. Kemudian, ada durasi waktu ujian yang ditentukan oleh guru dan admin.

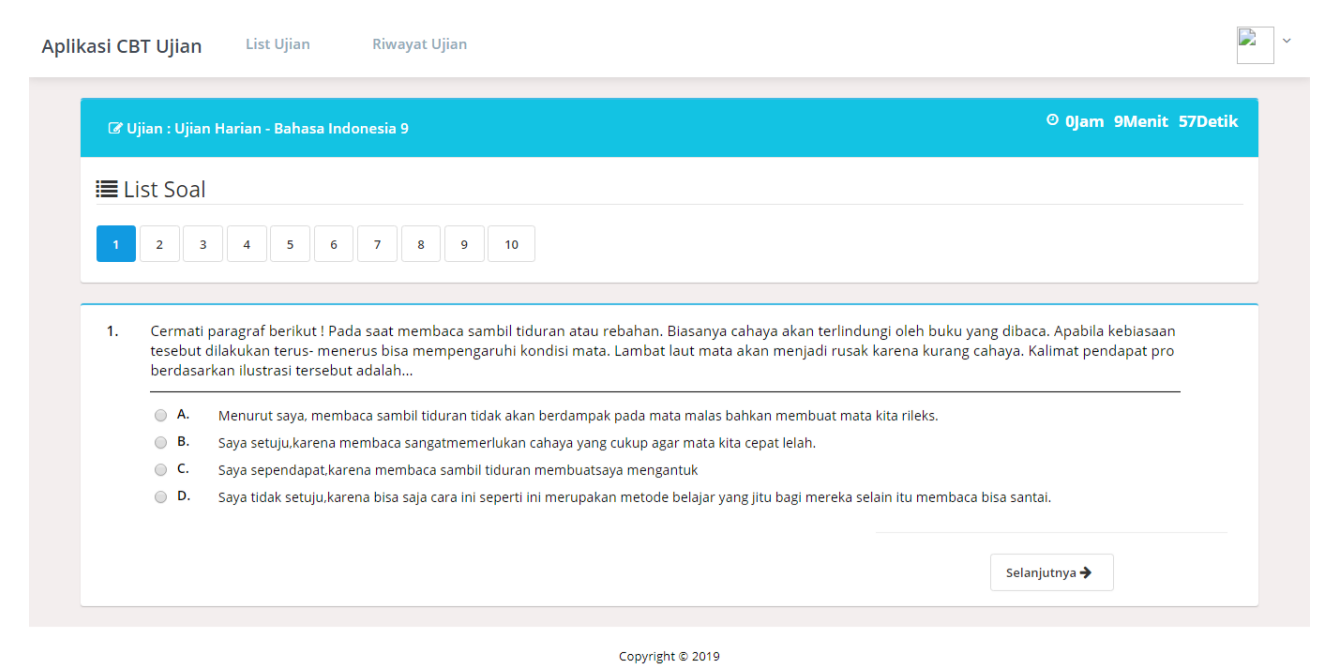

Gambar 5. Halaman Siswa

\section{f. Halaman Hasil Ujian (Guru)}

Halaman hasil ujian berisi penilaian sistem terhadap ujian yang dilakukan oleh siswa, guru akan mengetahui nilai siswa dan jumlah siswa yang mengikuti ujian serta siswa yang tidak mengikuti ujian. 


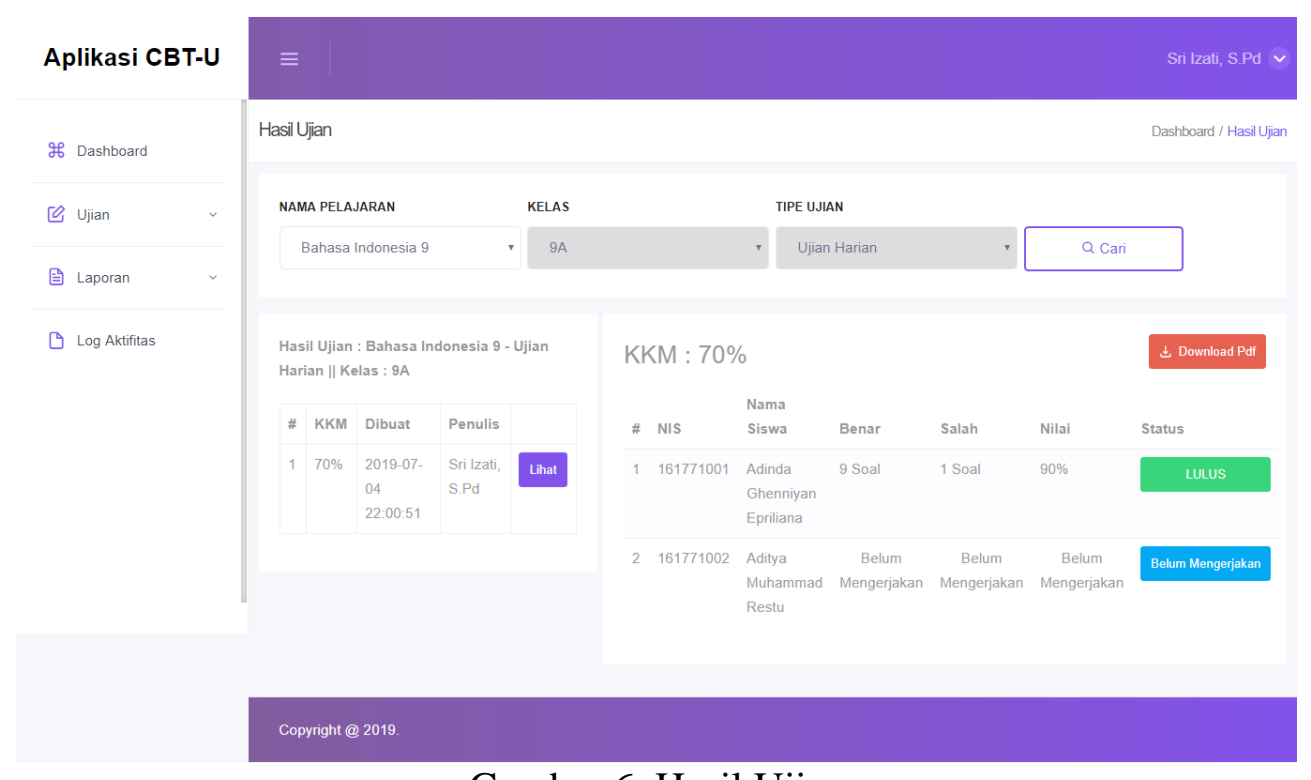

Gambar 6. Hasil Ujian

\section{Kesimpulan}

Berdasarkan hasil pembahasan yang dilakukan selama penelitian maka diperoleh kesimpulan, diantaranya : 1) Aplikasi Aplikasi computer-based test (CBT) ujian dinilai efisien karena pembuatan soal melalui guru atau admin secara langsung tanpa harus melalui perantara, setelah ujian dilaksanakan karena sudah memanfaatkan komputer dan internet sehingga tidak membutuhkan kertas untuk ujian. 2) Aplikasi computer-based test (CBT) ujian memiliki fitur acak soal yang dapat mengurangi kecurangan siswa yang mencontek saat ujian berlangsung. 3) Aplikasi computer-based test (CBT) ujian memiliki fitur nilai yang dapat menampilkan nilai secara otomatis sehingga mengatasi waktu koreksi jawaban ujian yang memakan waktu dan meminimalisir kesalahan penilaian.

\section{Daftar Pustaka}

[1] Leonardi Paris Hasugian, "Perencanaan Strategi Kolborasi Universitas untuk Mengoptimalkan Kerjasama U2U”, JATI, vol. 6, no. 1, 2016.

[2] Rangga Sidik dan Leonardi Paris Hasugian, "IT/IS Strategy dan E-Strategy: Kajian dalam Ruang lingkup Perusahaan", JAMIKA, vol. 6, no. 2, 2016.

[3] A.J Romiszowski, "Designing instructional systems: Decision making in course planning and curriculum design", Routledge, 2016.

[4] George M. Marakas dan James A. O'Brien, "Pengantar Sistem Informasi", Edisi 16, Jakarta: Salemba Empat, 2017.

[5] Jogiyanto, “Analisis dan Desain Sistem Informasi: Pendekatan Terstruktur Teori dan Praktik Aplikasi Bisnis, Yogyakarta : Penerbit Andi, 2005.

[6] Ditha Febriannisa dan Leonardi Paris Hasugian, "Perancangan E-Learning pada SMK Negeri 1 Bandung”, ULTIMA InfoSys, vol. 8, no. 2, pp. 62-68, 2017.

[7] J C Wibawa dan E Edah, "Aplikasi E-Learning di SMP Negeri 46 Bandung”, Sistem Informasi.

[8] Prof. Dr. Azhar Arsyad. M.A, "Media Pembelajaran”, Depok: Raja Grafindo, 2013.

[9] Mhd Arief Hasan, Supriadi, dan Zamzami. "Implementasi Algoritma Fisher-Yates untuk Mengacak Soal Ujian Online Penerimaan Mahasiswa Baru (Studi Kasus: Universitas Lancang Kuning Riau)", Teknosi, vol. 3, no. 2, 2017. 
[10] Roger S. Pressman, "Rekayasa Perangkat Lunak (Pendekatan Praktisi)" Edisi 7: Buku 1, Yogyakarta: Andi, 2012. 